\title{
THE EFFECT OF 2: 2-DIPHENYL-4-N-HEXAMETHYLENIMINO- BUTYRAMIDE METHIODIDE ON EXPERIMENTAL CHRONIC ULCER IN GLANDULAR STOMACH OF RATS
}

\author{
Takashi HISAMATSU, Tadashi NAKAZAWA and Takemi KOEDA \\ Research Laboratories, Meiji Seika Kaisha, Lrd., Kohokt-ku, Yokohama
}

Received for publication August 28, 1970

2: 2-Diphenyl-4-N-hexamethylenimino-butyramide methiodide (R-661) is one of the series of substituted diphenylpropyl-amines synthesized by Janssen et al. and is a typical quaternary atropine-like substance (1-9). It has anticholinergic activity, namely, parasympatholytic activity.

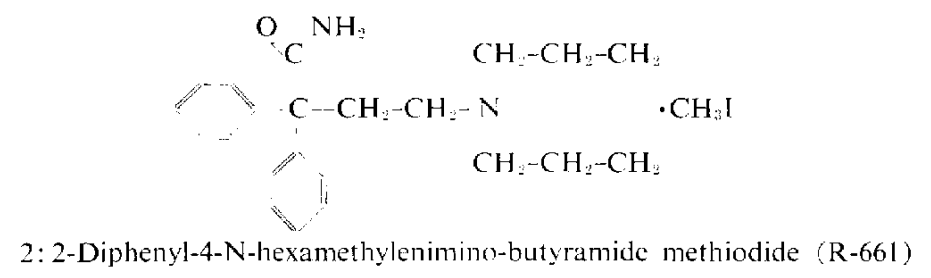

Additionally, Janssen et al. reported that this compound showed the excellent gastrointestinal absorption and inhibited the formation of experimental gastric ulcer in rats (9).

In the present experiments, an attempt was made histo-pharmacologically to evaluate the curative effect of R-66I on experimental ulcers in glandular stomachs of rats.

\section{MATERIALS AVD METHODS}

1. Induction of chronic wher in the stomach of the rat

Induction of the gastrointestinal ulcer was done according to the clamping-cortisone method (10).

Twenty-four male rats of Wistar strain weighing from 200 to $250 \mathrm{~g}$ were used. All animals were, after fasting for 24 hours, anesthetized with hexobarbital sodium and the stomach was exposed by laparotomy. Thin aluminum metal plate, $12 \times 4 \mathrm{~mm}$, was doubled, and clamped over the two pieces of gauze at the fundic serosal side of $3 \mathrm{~mm}$ to glandular portion from the limiting edge in the stomach. After the clamping site was disinfected, the incised abdominal wall was closed with Michel's clips. After 24 hours, the laparotomy was performed again, and the clamping metal plate and two pieces of gauze were removed. Then laparotomized abdominal wall was sutured again. Cortisone was injected intramuscularly at a dose of $70 \mathrm{mg} / \mathrm{kg} .7$ successive days from the first operation. The animals fasted for a period of 3 days ( 72 hours); the previous day of clamping, the day of clamping and the next day. 


\section{Agents and methods of administration}

The agents used were $\mathrm{R}-661$ and tinaline (diethylaminoethyl-diphenyl-glycolate methobromide: C. H. Bofhrivger SoHn, \& Y Mundeh! Selyakl C.o Ltd.) as a control agent. R-661 and Finaline were dissolved in physiological saline and administered subcutaneously at a dose of $3 \mathrm{mg} / \mathrm{kg} / \mathrm{day}$, for 15 to 30 days after the hinish of cortisone administration.

Twenty-four animals were divided into six groups as indicated in Table 1.

TARLE 1. The experimerital groups and administered agents.

\begin{tabular}{clcc}
\hline Groups & Agents & $\begin{array}{c}\text { Duration of } \\
\text { administration (days) }\end{array}$ & $\begin{array}{c}\text { Administration } \\
\text { dose }\end{array}$ \\
R-1 & R-561 & 15 & $3 \mathrm{mg} k \mathrm{~kg}$ day \\
R-2 & R-661 & 30 & $3 \mathrm{mg} \mathrm{kg}$ day \\
F-1 & Finaline & 15 & $3 \mathrm{mg} \mathrm{kg}$ day \\
F-2 & I Finaline & 30 & $3 \mathrm{mg} k \mathrm{~kg}$ day \\
C-1 & Saline & 15 & $1 \mathrm{ml} \mathrm{kg}$ day \\
C-2 & Saline & 30 & $1 \mathrm{ml} \mathrm{kg}$ day \\
\hline
\end{tabular}

The animals were sacrificed and the siomach was extirpated after 15 and 30 days from the beginning of the agent administration. The extirpated stomachs were fixed in $10^{\prime \prime}$ " formaldehyde solution.

\section{Histological examination}

After the macroscopical observation of the extirpated stomachs (Table 2). the specimens obtained from them werc made into microscopical preparation by means of haematoxylin-eosin double staining and examined minutely (Table 3). Histological examinations of the gastric ulcer were performed according to the method and fincings reported by Unehara et al. (10).

\section{RESLLTS}

Macroscopical measure of size of the gastric ulcer, shapes of the ulcer and gross histological findings are shown in Table 2.

An average size of the gastric ulcer measured macroscopically in each group was shown as the product of average length of major axis $\times$ average length of minor axis $\times$ average depth, of ulcer, in the most righi side column of Table 2. In Table 3, the histological findings and various determinant values of severity of ulcer by microscopical examination were summarized. The determined regions of ulcer in histological preparation and various indexes on severity of ulcer were as follows.

1: apparent defect of nucou: membrane-a, 2: defect of mucous membrane - b, 3: regeneration epithelia, $c_{1}-1 \cdot c_{:}=c, 4: s t u m p$ distance of mucsularis mucosa $=\mathrm{d}$, 5 : stump distance of muscularis propria $-\mathrm{e}, 6$ : thic':ness of ulcer fundus $-\mathrm{f}, 7$ : thickness of swelling region of ulcer margin $=\mathrm{g}, 8:$ ulcer index: $(\mathrm{b} / \mathrm{d}): 100=\mathrm{A}, 9:$ regeneration index of mucous membrane: $\{c(b-c)\} 100-B, 10$ : renewal degree of collagen fiber: $(: 20$ points $),(: 40$ points), ( I : 60 points $),(-+-; 80$ points). ( + : : 100 points $-C .11:$ synthetic cure index: $\{(100-\mathrm{A})-\mathrm{B}+\mathrm{C}, 3-\mathrm{D}, 12$ : average synthetic cure index in each group. 


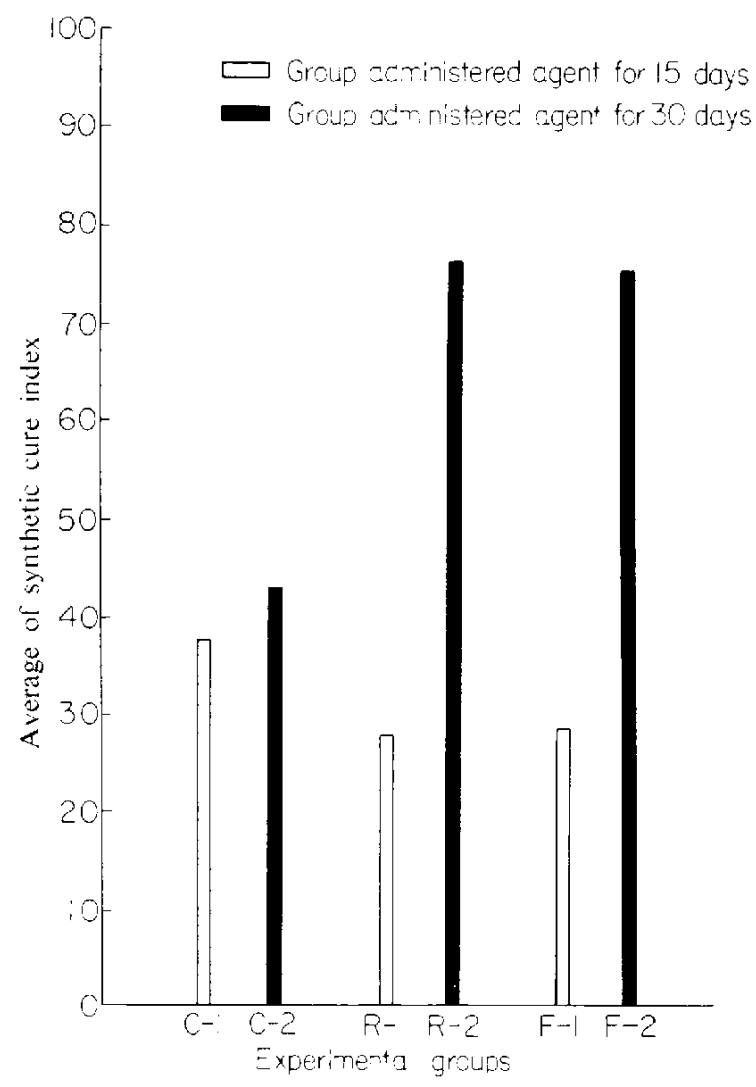

Fic. 1. Averages of synthetic cure index of the ulcers in each experimental group receiving the administration of R-66I, Finaline or physiological saline for 15 or 30 days.

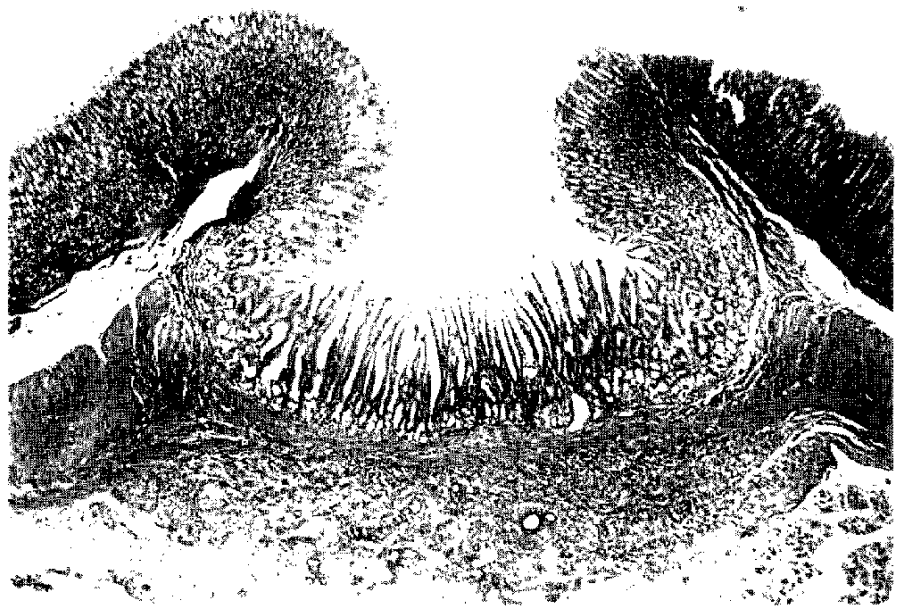

FIG. 2. Microscopic picture showing very high curative rate of ulcer in F-2 group. Ulcer index: 0, synthetic cure index: $90 .(\times 30)$ 


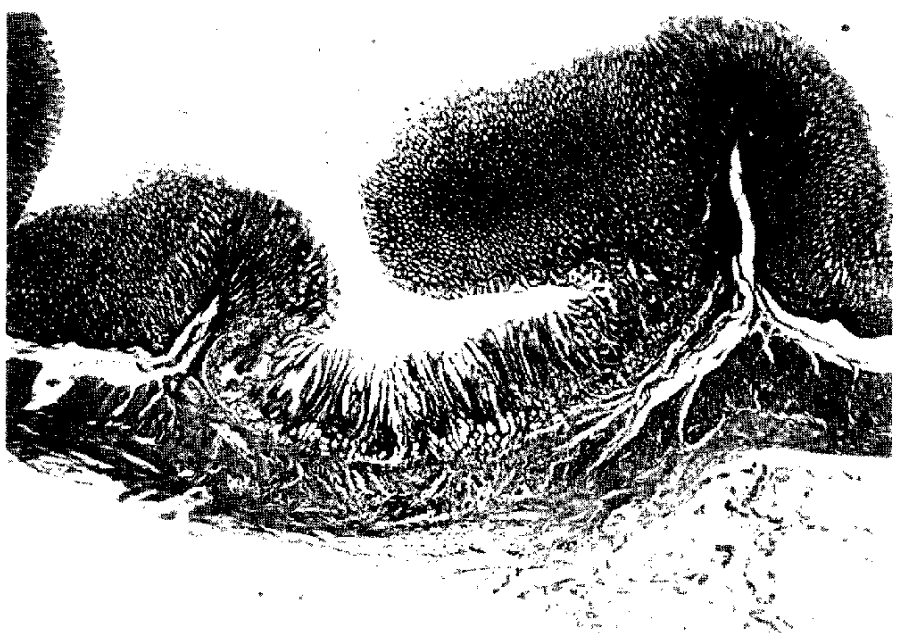

FIG. 3. Microscopic picture of another case showing very high curative rate of ulcer in F-2 group. Ulcer index: 0 , synthetic cure index: 100 . $(x \quad 30)$

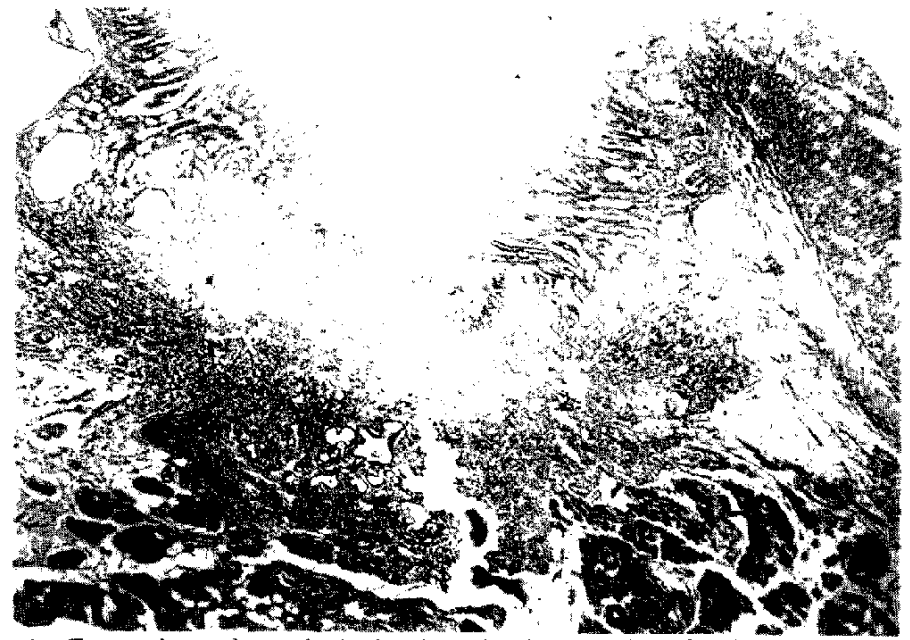

Fici. 4. Formation of atypical gland cavily in the ulcer fundus $(F-2)$. (

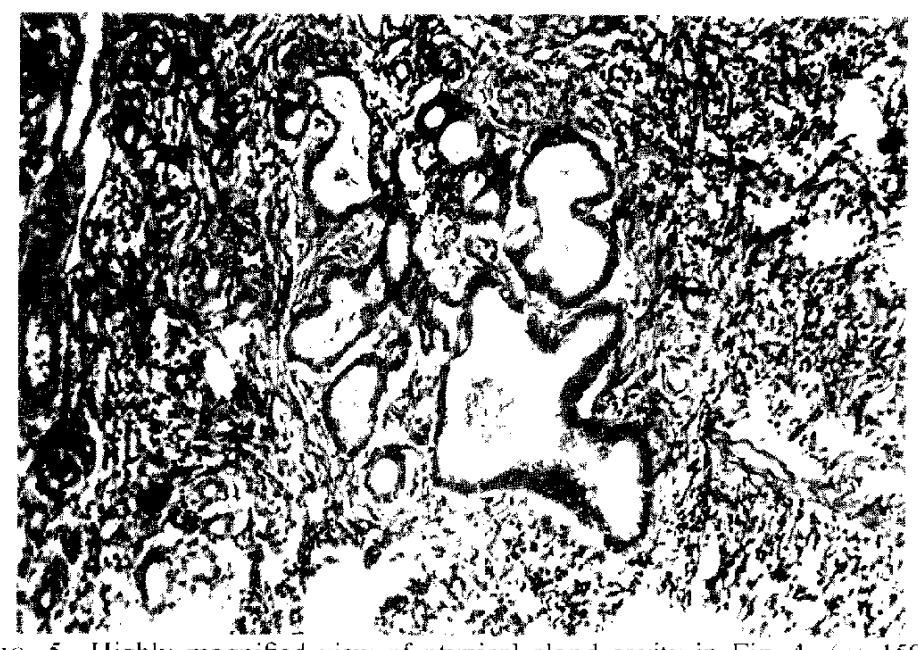

FIa. 5. Highly magnified view of atypical gland cavity in Fig. 4. ( 150 
As found clearly form Table 2, Table 3 and Fig. 1, the average synthetic cure index in R-2 group was higher than those in any other groups.

However, difference of synthetic curative degrees between R-2 group and F- 2 group was small. Renewal degree of collagen fiber in F-2 group was rather better than that in R-2 group. Especially, two preparations in $\mathrm{F}-2$ group showed very high curative ratios. In histological findings, they showed complete regeneration of mucous membrane and remarkable renewal of collagen fiber and muscle fiber in the ulcer fundus (Figs. 2 and 3), although they kept slight vestige of ulcers. One of them showed complete recovery of muscularis propria. However, as the other two cases in F-2 group showed unremarkable recovery of ulcers, they lowered average of synthetic cure index in this group. In histological findings, one of these cases showed the forming of atypical gland cavities in

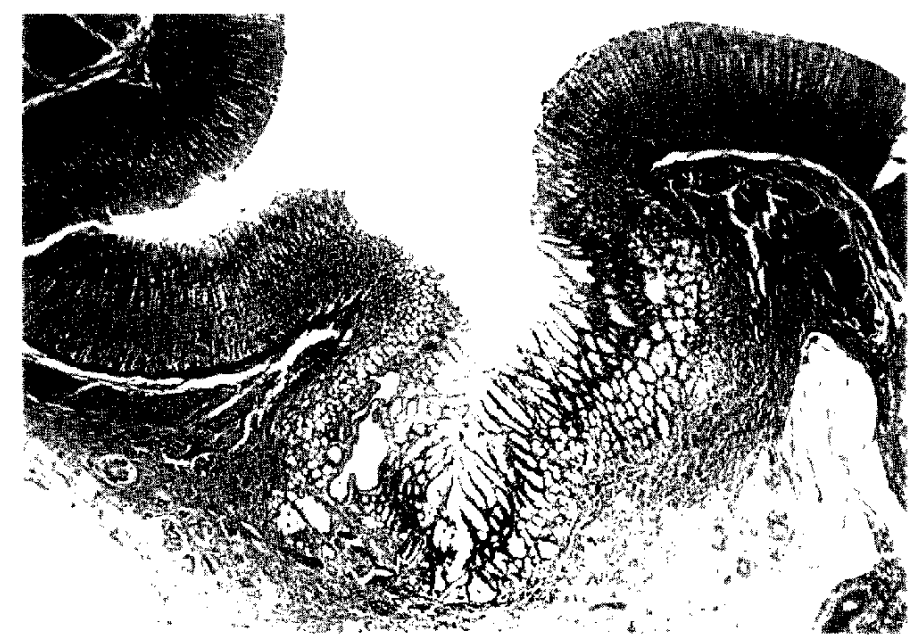

Fic. 6. Ulcer showing the excellent curative degree (R-2). Regeneration index of mucous membrane: 100 , synthetic cure index: $93.3 .(30)$

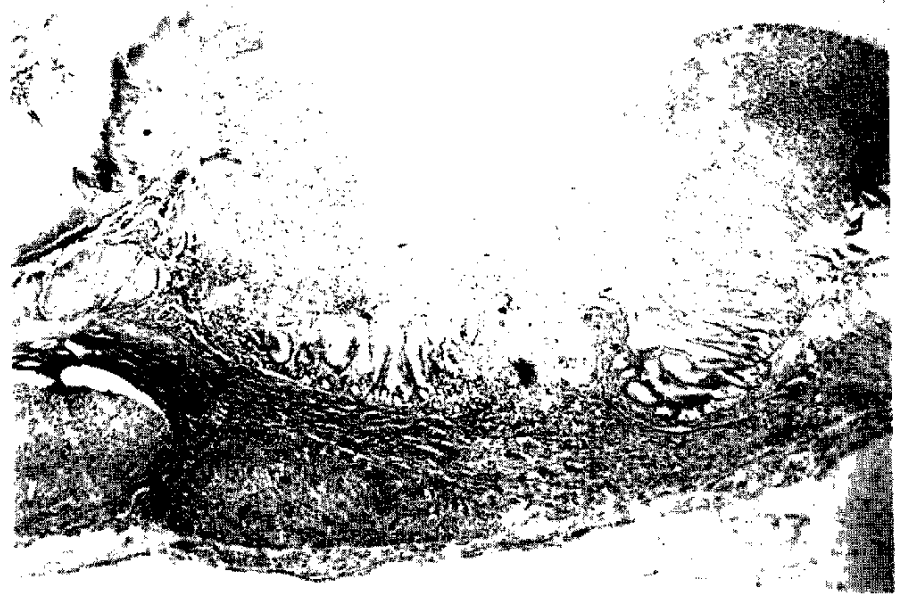

Fic. 7. The case showing considerable high curative degree of ulcer in C.-2 group. Regenerative degree of mucosa also is high. ( 30 ) 


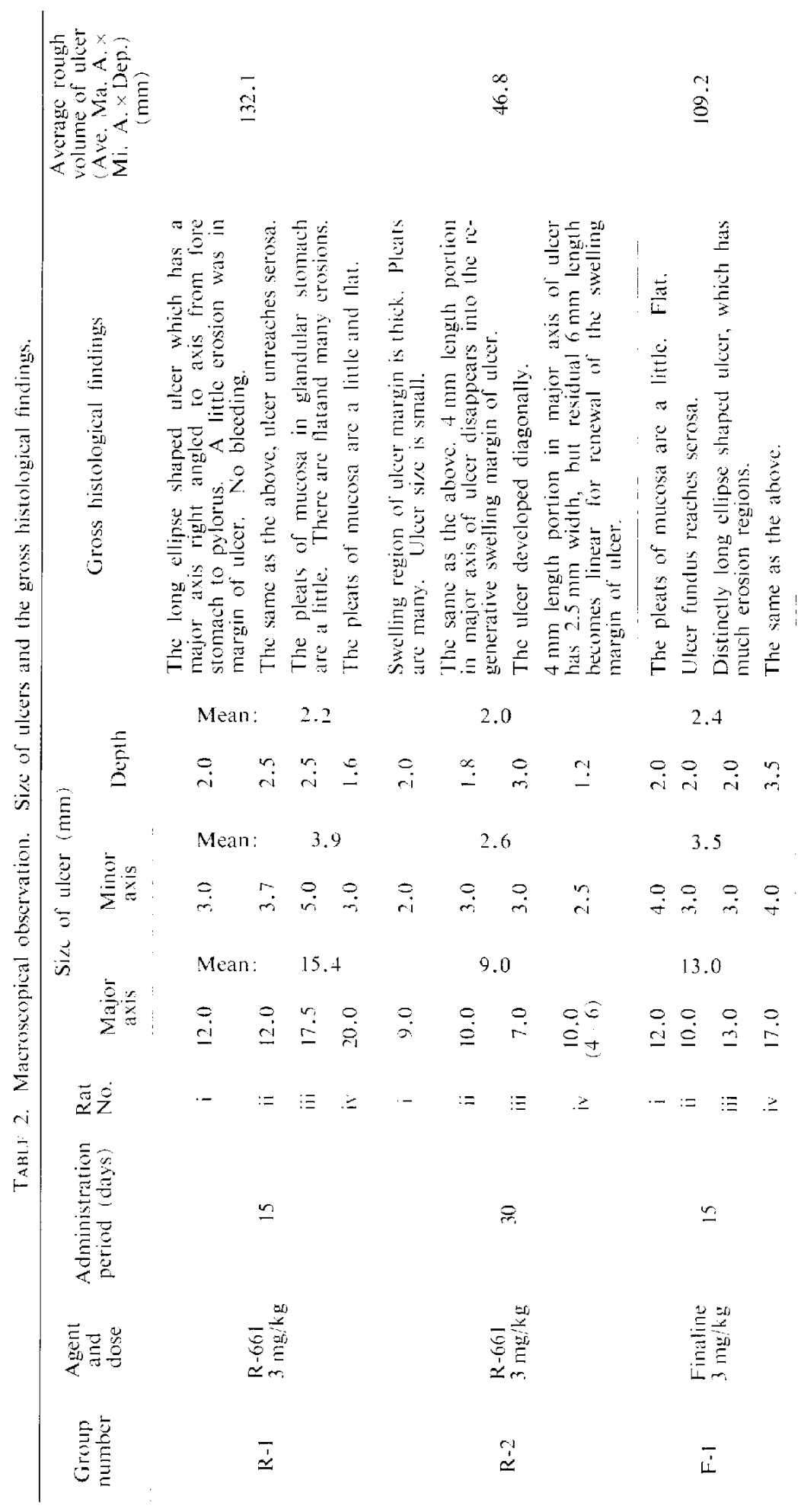




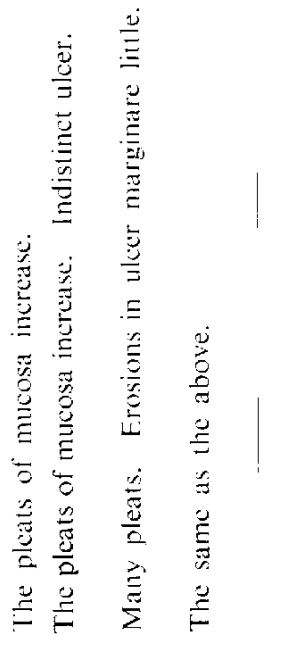

2.3

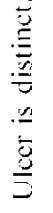

$\stackrel{?}{\Xi}$

0
0

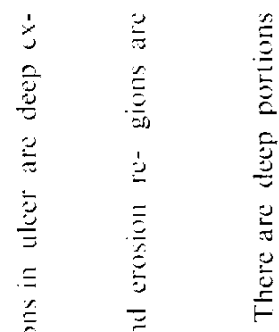

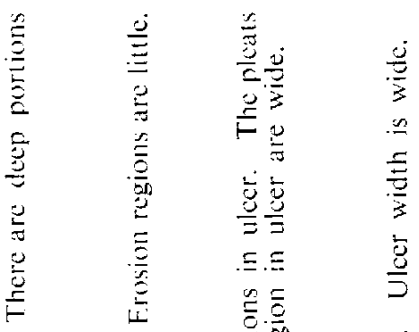

焦

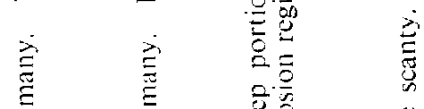

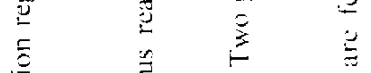

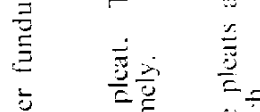

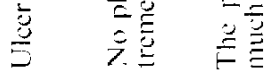

2.3

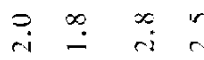

2.1

3.0

3.4

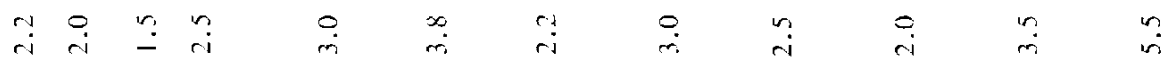

10.5

$3 \stackrel{2}{r}$
$-:=$

$\stackrel{乛}{\rightleftharpoons}$

冚焉

i
15.1

$\ddot{\theta} \quad \ddot{m}$

$\underset{\dot{x}}{\underline{\underline{x}}} \stackrel{0}{\underline{\underline{2}}}$

$\geq$

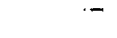

$n$

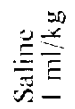

u $p$

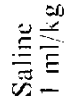

12.1

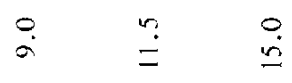

:

3 


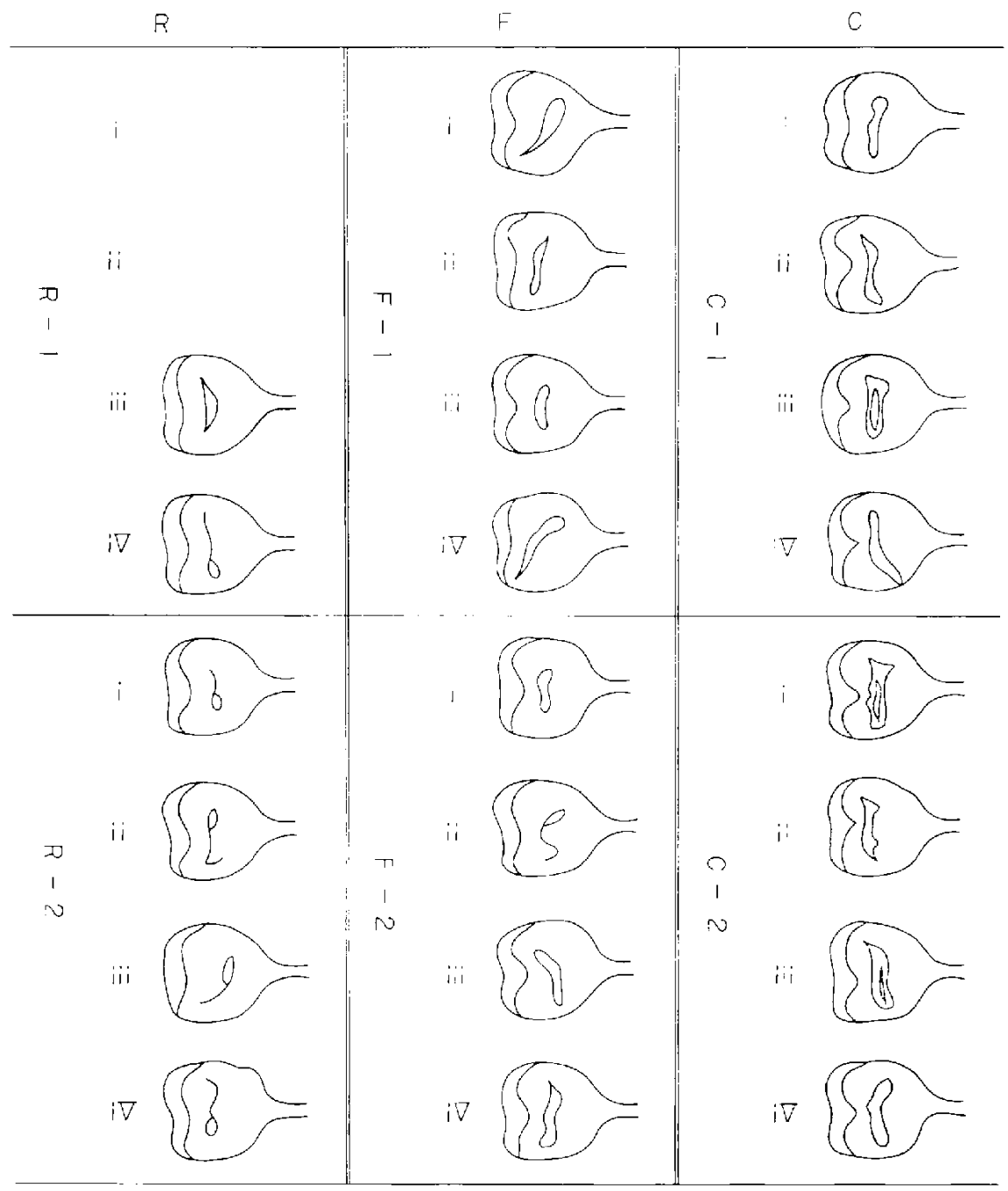


the ulcer fundus, which may change for the malignant lesion hencefoward (Figs. 4 and 5). One case in R-2 group showed the complete regeneration of mucous membrane, but renewal of the collagen fibers was not very remarkable al ulecr fundus and its adjacent regions (Fig. 6). Four cases in this group showed high average of synthetic cure indexes, and in histological findings, the recovery states of the ulcers were also excellent on the whole. These $\mathrm{F}_{-2}$ and R-2 groups showed considerably high curative ratio and good recovery appcarance in comparison with $\mathrm{C}-2$ group. The significant differences of the synthetic cure indexes between $\mathrm{R}-2$ group and F-2 group were not recognized. In C-2 group, animals showed uncertain curing states of ulcers. Two cases showed very low synthetic cure indexes, and others showed considerable high values (fig. 7). It was re-

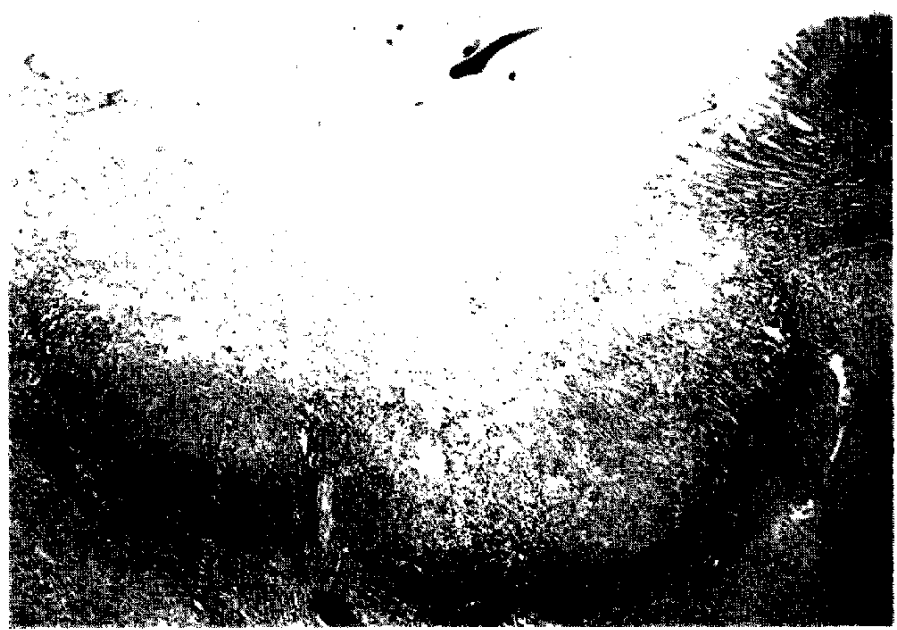

Fig. 8. Aberration of liver tissue into the ulcer fundus seen in one animal of C-2 group. Recovery degree of ulcer is small. ( $>30$ )

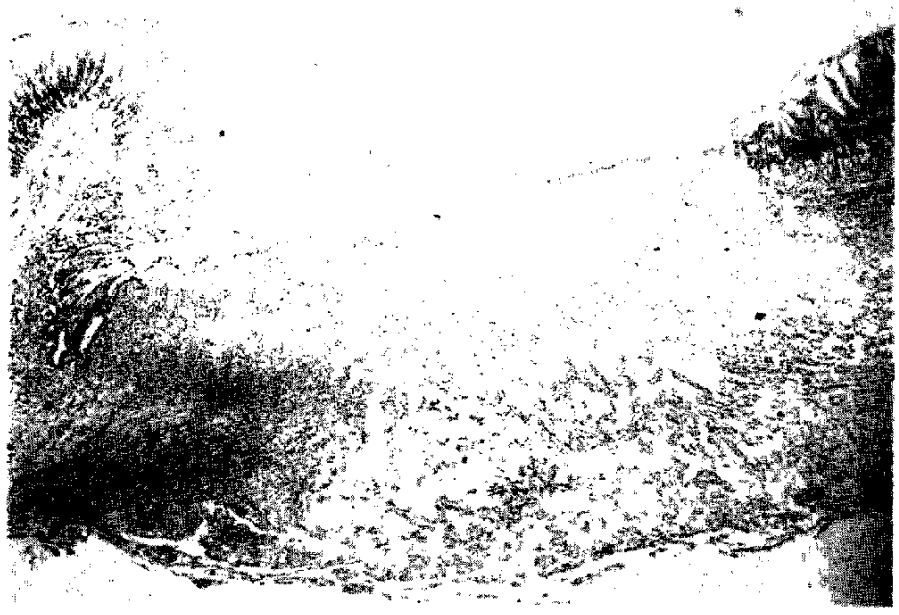

Fici. 9. Licer in the animal administered a dose of $3 \mathrm{mg} / \mathrm{kg} /$ day of $\mathrm{R}-66 \mathrm{I}$ for 15 days $(R-1)$. Renewal of fiber tissues in the ulcer fundus is unremarkable. $(30)$ 


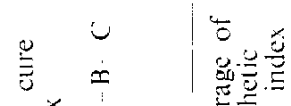

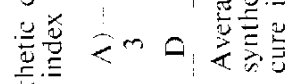

$\stackrel{c}{\rightarrow+1}$

$\stackrel{8}{\circ}$

$\stackrel{0}{0}$

$\stackrel{\Xi}{\Xi}$

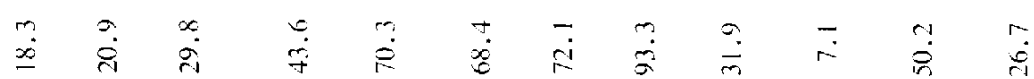

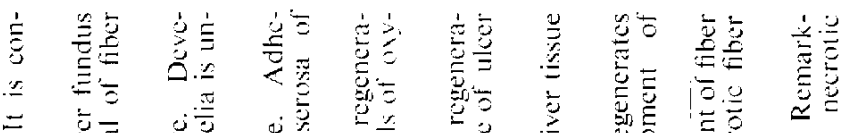

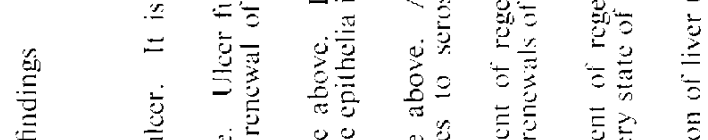

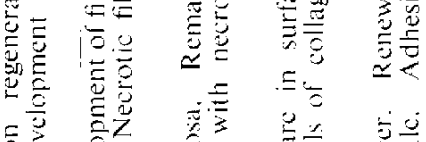

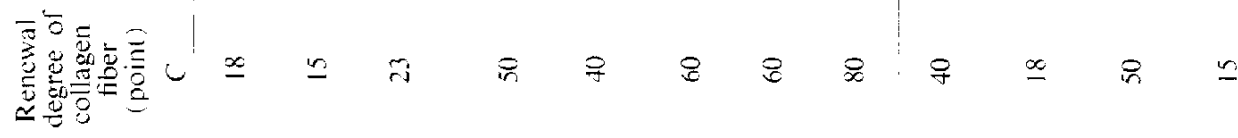

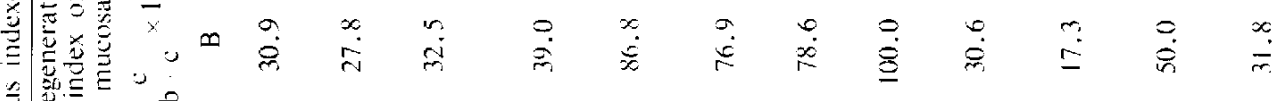
$\stackrel{\circ}{\simeq}$

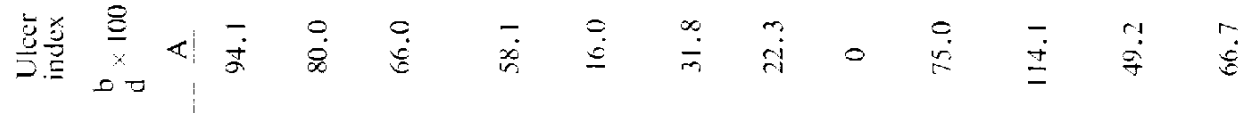

$\infty$ 志

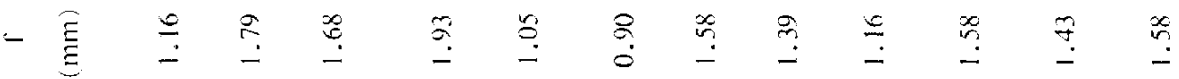

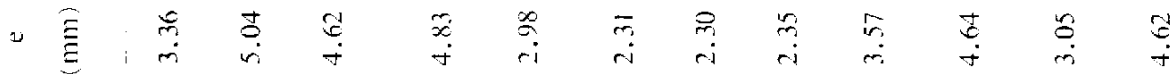

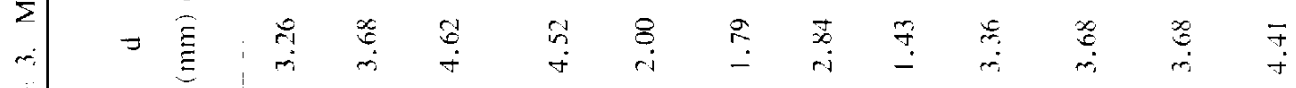

$\stackrel{2}{=} \underset{-}{-}$

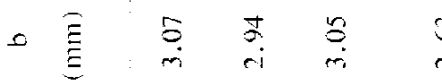

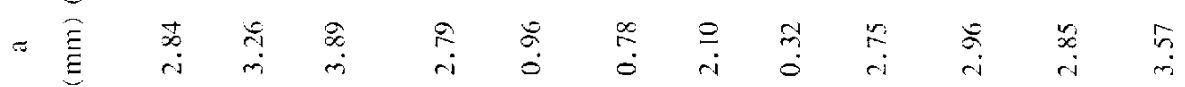

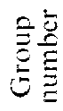




$$
\bar{r}
$$

$\underset{\sim}{*}$

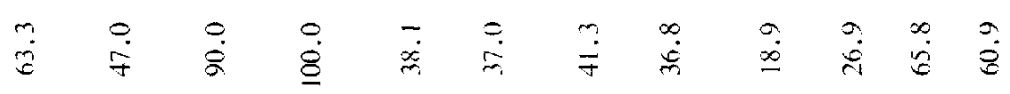

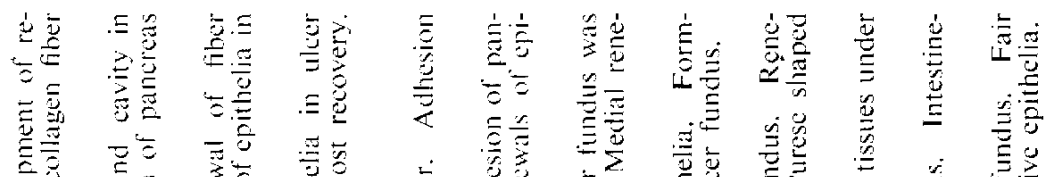

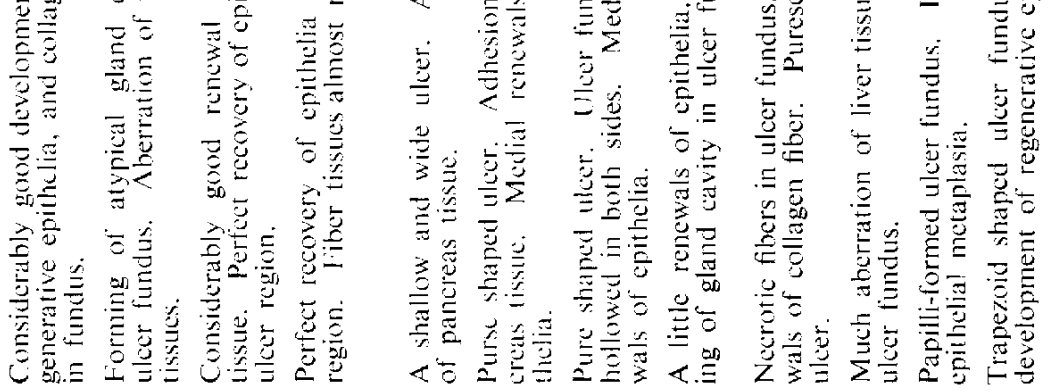

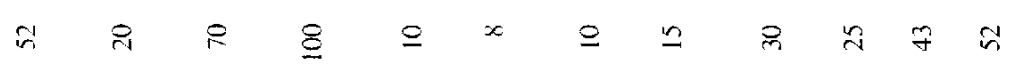

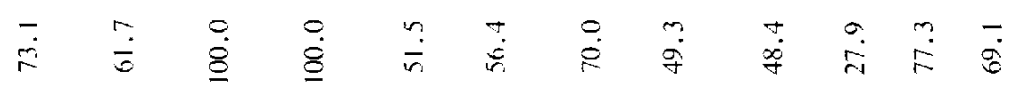

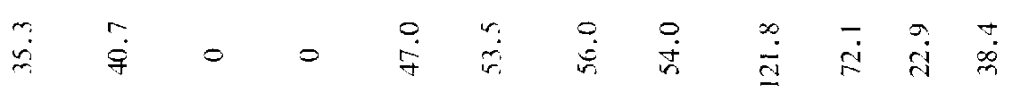

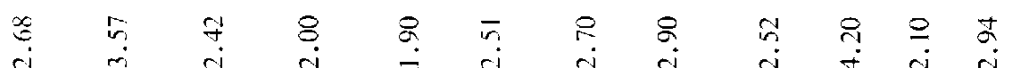

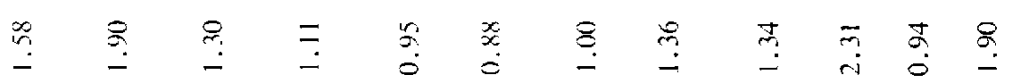

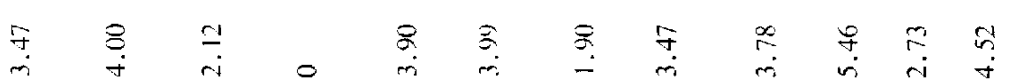

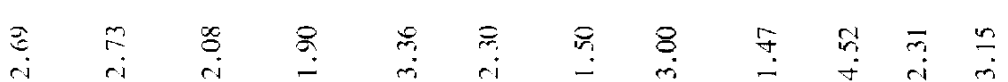

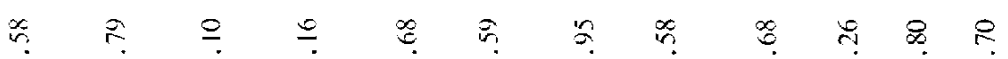

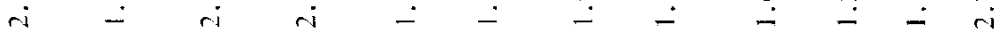

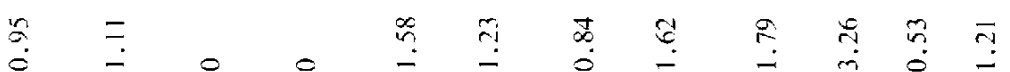

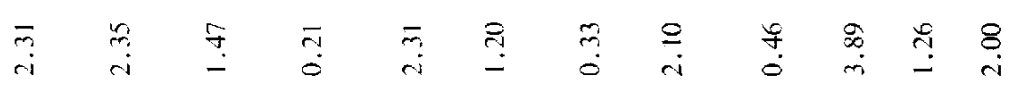

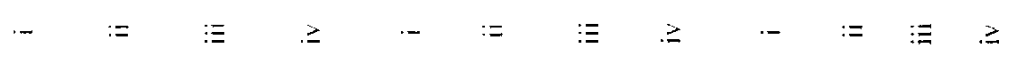
$\stackrel{4}{1}$ í 


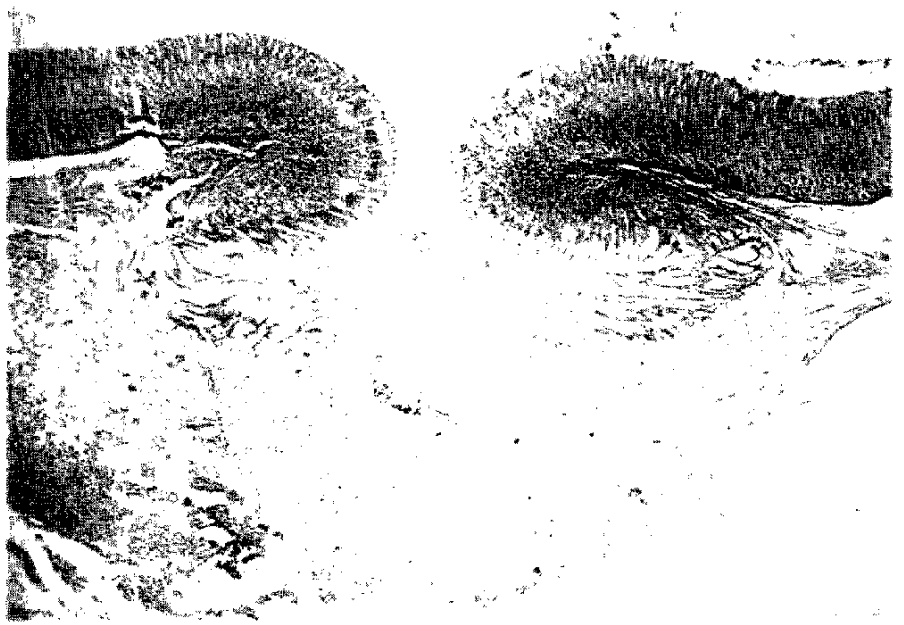

Fro. 10. The case showing the highest synthetic cure index of ulcer in $\mathrm{C}-1$ group. $(30)$

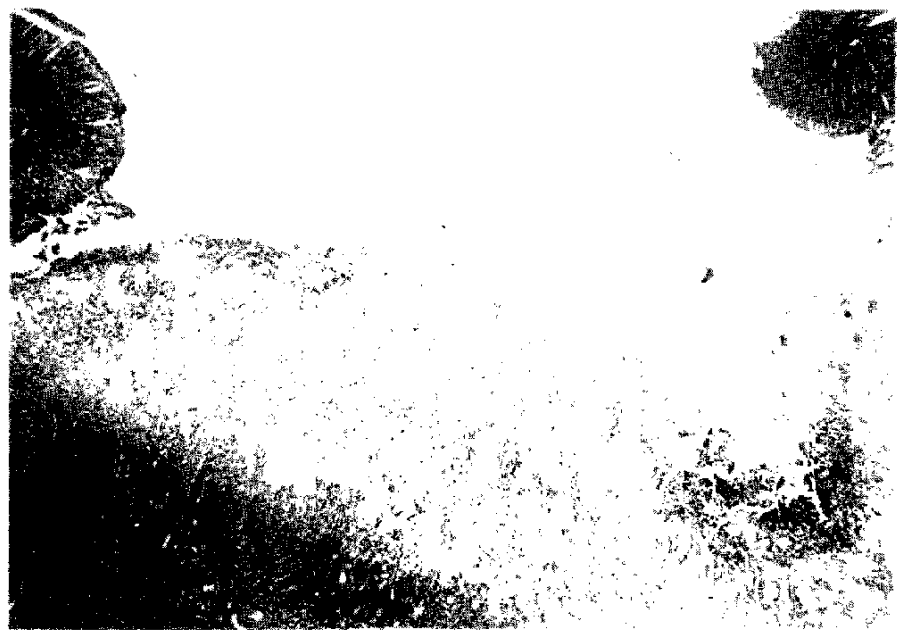

FIG. 11. Remarkable purse-shaped ulcer in the animal administered a dose of $3 \mathrm{mg} \mathrm{kg}$ day of Finaline for 15 days $(F-1)$. 30 ?

cognized in the histological findings that the values of defect of mucous membrane were larger than those of stump distance of the muscularis mucosat, so the ulcers showed typical purse-like shapes, and that liver tissues invaded into the ulcer fundus in most animals of this group (Fig. 8). In the groups treated with the agents for 15 days, R-1 group showed the lowest curative ratio (Fig. 9), although the difference from the curative ratio of F-I group was slight (Fig. 1). C-1 group showed the highest curative rate within the groups treated for 15 days. This corresponded with the fact that R-1 group and F-1 group showed larger average of rough volume of ulcers than that of $\mathrm{C}-1$ group as shown in Table 2 . When the result of the $\mathrm{C}-1$ group was compared with that reported by Umehara and Tabayashi et al., uker index, regeneration index of mucous membrane and synthetic cure index were very high, although the renewal degrees of collagen fiber were the same as Umehara et 
al. reported. These results also agreed with the histological findings. The development of the regenerative epithelia were remarkable ats compared with R-1 and F-1 groups, but renewals of collagen fibers werc unremarkable (Fig. 10). In R-1 and F-1 groups, some animals showed a good recovery but others not. Accordingly, their average synthetic cure indexes were lowered. Particulary, in one case of F-I group, the defect of mucous membrane was notable, and the ulcer index was larger than 100.

The ulcer showed the striking purse-shaped feature (Fig. 11) and its synthetic cure index was 7.1. In these control groups, the difference between average of synthetic cure index in C-1 group and that in C-2 group was small. The recovery of ulcers has hardly progressed in later half of 30 days of physiological saline administration. On the con-

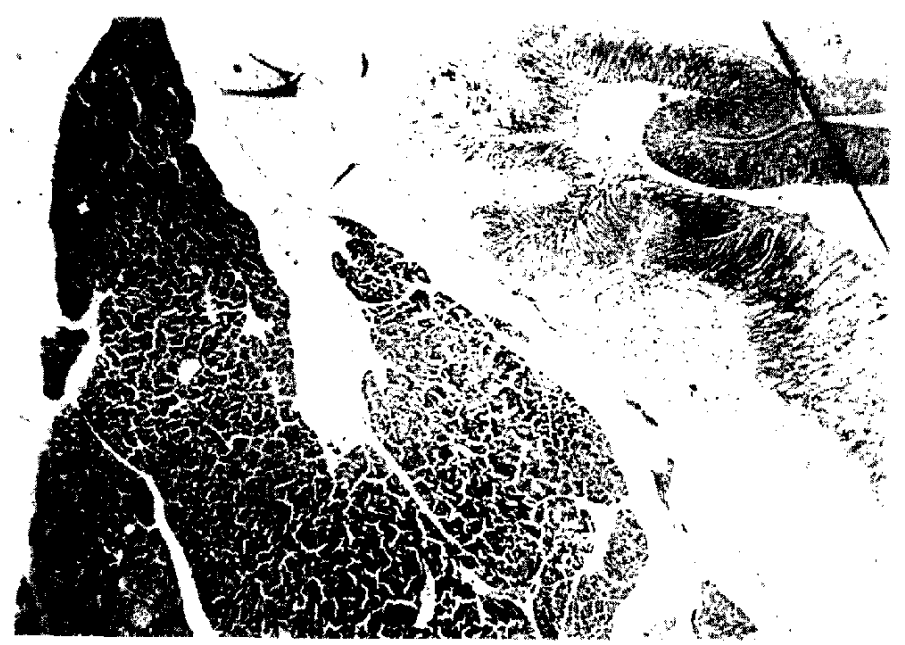

Fici. 12. Adhesion of pancreas tissue to the fundus region of ulcer seen in one animal of $\mathrm{R}-1$ group. ( 30 i

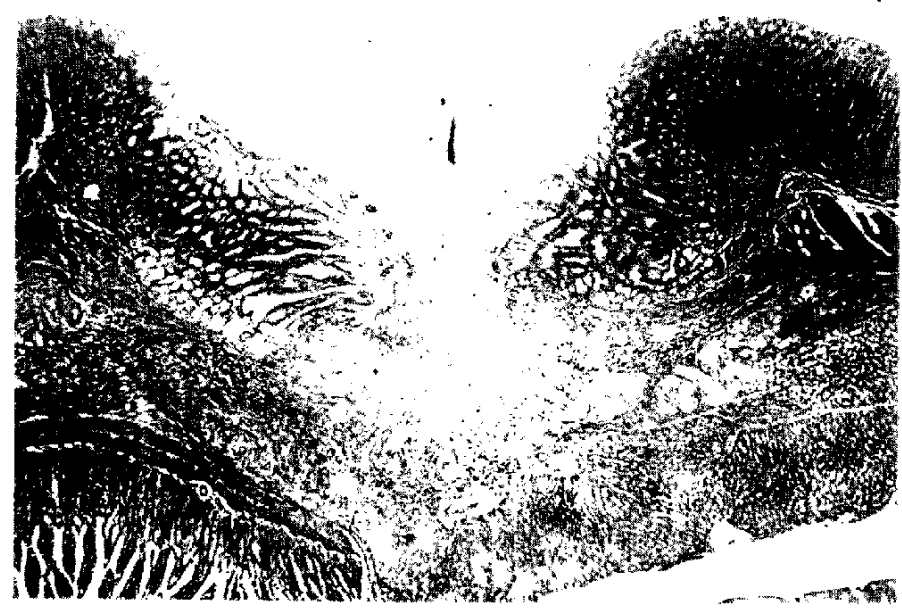

Fici. 13. Adhesion and abcration of liver tissues into the fundus region of ulcer in the animal administered a dose of $3 \mathrm{mg} / \mathrm{kg} / \mathrm{day}$ of $\mathrm{R}-661$ for 30 days ( $\mathrm{R}-2)$. ( 30$)$ 
trary, in R-661 and Finaline administration groups, the curative rates of ulcers during from the 16 th to the 30 th day of the agents administration were extremely high.

\section{DISCLSSION}

Various procedures have been reported for producing experimental gastrointestinal ulcers (11-24). Recently, it was demonstrated that considerably severe ulcers were produced by a small dose of reserpine combined with stress such as restraint (25), conflict (26), electrical stimulation of the hypothalamus $(27,28)$ and electrical shock through a grid in the floor $(28,29)$. However, the incidence of ulcers by these methods was low and the severity of the ulcer was uncertain. Most of these ulcers were acute and recovered spontaneously within 2 weeks. Therefore, the ulcers induced by the above methods seemed to be unsuitable for the examination of the curative effect of drugs, although they might be suitable for the examination of the preventive effect of drugs.

By the clamping-cortisone method. the ulcer was produced easily in small animals, exactly in all of experimental animals and with a certain size or severity. In addition. the ulcer induced by this method is similar to the human ulcer from the various viewpoints including the histological findings. Therefore, this is considered to be one of the useful methods for bioassay of the curative agents of ulcers.

In the present experiment, the curative effect of $R-661$ on the ulcers produced by this method was histopharmacologically evaluated according to the criteria for bioassay contrived by afore mentioned investigators (10).

Janssen (9) reported that R-661 showed the preventive effect on the Shay rat uleer and the hunger ulcer of the rat. In addition, Takagi et al. (30) reported that an anticholinergic drug such as atropine methylbromide showed the most excellent effect on the prevention of development of the ulcer but it had only a weak effect on the existing ulcers, and glutamine and gefarnate which were almost ineffective on the prevention of development of the ulcer were more effective than antacids and the anticholinergic drug on the cure of the ulcer.

As evidenced in the experimental results, R-66l also showed distinctly the curative effect in a dose of $3 \mathrm{mg} / \mathrm{kg} /$ day for 30 days. The average of synthetic cure index was 76.0 and the regeneration index of mucosa also showed considerably high average. Moreover, the recovery state of ulcer was very excellent in the histological findings.

Recently, Okabe et al. (31) reported that sulpiride considered to be a sympatholytic promoted the cure of chronic ulcer produced by the injection of dilute acetic acid into the rat gastric wall, and they mentioned that ganglioplegic or parasympatholytic agents inhibited the gastric secretion (32) but sulpiride did not inhibit such a function.

R-66l that is anticholinergic agent i.e. parasympatholytic agent inhibited the gastric secretion. This fact was recognized by the experiment using rats in our laboratory (33).

From the above facts, as the mechanism of action of R-661 on the existing ulcer, it might be considered that R-661 blocked the impulse conduction in parasympathetics and protected indirectly the regenerative mucosa from the encroachment of gastric juice at 
the time of the recovery of ulcers. Whether $\mathrm{R}-66 \mathrm{l}$ promotes directly the regeneration of mucosa and the renewals of collagen fiber in the recovery of ulcers or not will be clarified through further investigation.

Considering the facts that the preventive effect of R-661 on the formation of stress ulcers by Takagi et al.'s method (30) was previously demonstrated in our laboratory, it may be inferred that R-661 shows both the curative and preventive effects on the experimental gastrointestinal ulcers, and the curative effect increases according as the duration of agent administration becomes longer than a certain duration.

Finally, authors add that pancreas and liver tissues were found to adhere to or stray into the fundal region of ulcers in most of animals of each experimental group, and it appeared to influence undesirably the recovery of ulcers (Figs. 8, 12 and 13).

\section{SUMMARY}

Anti-ulcer effect of R-661 which is one of the series of substituted diphenylpropylamines and possesses anticholinergic activity was studied on the chronic gastrointestinal ulcer produced by the clamping-cortisone method. R-66l showed distinctly the curative effect in subcutaneous administration of a dose of $3 \mathrm{mg} / \mathrm{kg} /$ day for 30 days, and the average synthetic cure index was 76.0. Moreover, the recovery state of ulcers was very excellent in the histological findings.

The curative effect of R-661 on the existing ulcer seems to increase according as the duration of administration becomes longer than a certain duration.

\section{REFERENCES}

1) Jongh, D.K. Janssan, P. and Pronsdi-HartzFMa, E.G.: Acta physiol pahrmac. néerl. 3. 331 (1954)

2) Jovifl, D.K., Proosdu-Hartzlma, E.C. Avd Javssen, P.: Archs int. Pharmacodyn. Thér. 103, $100(1955)$

3) JAGENFAL, A. AND JANSSEN, P.: Archs int. Phammacodyn. Ther, 106, 199 (1956)

4) Javssen, P., Zivkovic, D., Jagitntau, A. Axd Divote, P.: Archs int. Pharmacodyn. Ther. 107, $194(1956)$

5) Javssid, P. AND Jagliveau, A.: Experientia 12, 293 (1956)

6) Ianssil, P., Jagrenel, A., Proosdi-Hartzfma, E.G. and Jongin, D.K.: Acta physiol, pharmar. néerl. 7, 373 (1958)

7) Jaissex, P., Jagfineau, A., Demola, P., Wistierivgh, C., Rafymaeklrs, A., Wolters, M., SaveZuk, ST., Hermais, B. AND Loovais, J.: I. Med. Pham. Chem. 1. 105 (1959)

8) Janssiv, P., Drmor -, P., Jaghntau, A. avo Loomans, J.: J. Med. Pharm. Chem. 1, 187 (1959)

9) Jaxsse., P.: Private Communication, The Pharmacology of $R$-66/ (1960)

10) Umilara, S., Tabayashi, T., Simbuya, E., I10, H., Simmizu, M. and Koshilish, Y.: Chimo 47. 397 (1965)

11) Shay, H., Komarov, S.A., Ffls, S.S. And MeranzF, D.: Gastmenterology 5, 43 (1945)

12) Cahle, R.L. and TVlde, L.M.: Proc, Soc. exp. Biol. Med. 78, 707 (1951)

13) Hambolrcitr, W.F., Calvin, L.D. and Hollahan, D.A.: J. Pharmac. exp. Ther. 106, 392 (1952) 
14) Bla.vchi, R.B, AND COOK, D.L.: Gastrenterology 47, 409 (1964)

15) Kahn, D.S., Mflivilit, J.P. and Skoryan, S.S.: Am. J. Pathol. 38, 73 (1961)

16) Kahn, D.S. and Skorynd, S.S.: Am. I. Pathol. 38, 177 (1961)

17) Code, C.F. and Varco, R.L.: Proc. Soc. exp. Biol. Med. 44, 475 (1940)

18) Radolco, T.C., Latastr, D.C. avd Rogig, E.C.: Arzhzim. Forsch. 10, 588 (1960)

19) INGli D.J., Prestrud, M.C. And Nizauls, J.E.: Am. J. Physiol. 16, 171 (1951)

20) Robrir I, A. and Nezamis, J.E.: Proc. Soce exp. Biol. Med. 99, 443 (1958)

21) Rossi, G.: C. r. Séanc Soc. Biol. 150, 2124 (1956)

22) Wintile, II.A.: Am. J. Physiol. 147, 228 (1946)

23) Br.ATtIE, J.: Can. Med. J. 26, 278 (1932)

24) Watanabe, K.: Chem. Pharm. Bull, 14, 101 (1966)

25) Hartry, A.L.: J. comp. Phywiol. Psichol. 55, 719 (1962)

26) Sawrey, J.M. and Swarty, W.L.: J. comp. Physiol. Psychol. 57, 307 (1964)

27) Nishilaki, H., Yamamoto, K. A.id Kido, R.: Folia pharmac. jap. 60, 146 (1964)

28) KIDO, R.: Brain and Nerve 19, 467 (1967)

29) Dolluchi, M.: Jap. J. Pharmac. 18, 130 (1968)

30) Takagi, K. avd Okam, S.: Jap. J. Pharmac. 18, 9 (1968)

31) Okabl, S., Sajiki, R. and Takagi, K.: Phalmacometrics 3, 310 (1969)

32) TAKAGI, K. A\D OKaBi:, S.: Europ. J. Pharmac. 5, 263 (1969)

33) Koeda, T., Shibata, U., Nakazalya. T.. Asauka. H. and Yamakami. K.: Clintical Report 4. $176(1970)$ 